\title{
Mobile Media: Towards a Definition and Taxonomy of Contents and Applications
}

\author{
http://dx.doi.org/10.3991/ijim.v6i2.1880 \\ C. A. Scolari ${ }^{1}$, Aguado, J. M. ${ }^{2}$ and Feijóo, C. ${ }^{3}$ \\ ${ }^{1}$ Universitat Pompeu Fabra, Barcelona, Spain \\ ${ }^{2}$ Universidad de Murcia, Spain \\ ${ }^{3}$ Universidad Politécnica de Madrid, Spain
}

\begin{abstract}
The paper is grounded in the idea that a theory of mobile media, like that of any other scientific discourse, must be built on solid conceptual and taxonomical bases. Within this context the paper brings together previous fragmented approaches to studying mobile media, analyses them, and develops a set of definitions and classifications of contents and applications in order to consolidate the construction of a robust mobile media theory. The paper finishes with a reflection on the ongoing mutations of this field and their implications, suggesting that scholars need to rethink the basic concepts behind their theories.
\end{abstract}

Index Terms-mobile media, mobile content, mobile applications, mobile news, mobile advertising, mobile books, mobile music, mobile television, mobile games

\section{INTRODUCTION}

The digitalization of communications has gone through two phases. The first one was characterized by the spread of the World Wide Web in the 1990s and the subsequent mutations of different spaces of social life, from economy to education, politics and culture. The second phase started in the 2000s with the transformation of the Web itself_-passing from web 1.0 to web 2.0 [1] — and the big bang of new mobile devices, from smartphones to tablets [2][3][4][5]. The introduction of the iPhone in 2007 and the iPad three years later created a new standard for mobile communications ${ }^{1}$ and mobile media in particular. According to Featherstone:

More and more people are watching Internet pod-casts, video clips and pop-ups and listening to music from their cell phones and other mobile devices. This greater capacity for switching modes, enhanced flexibility and integration means that media are not just more mobile and work outside the office and home: the new media are also more interactive as cheaper multi-functional devices enable greater possibilities for creating, recording, editing, storing and archiving media contents (TV programmes, movies, music, images, textual data) [6].

The objective of this article is to introduce and discuss different definitions and classifications of mobile communication contents and applications. Why classify mobile contents and applications? Why is it so important to develop a taxonomy of them? Why not just analyse the

\footnotetext{
${ }^{1}$ Mobile communications is the most general term and encompasses both voice and data services. In this text, however, we have preferred to use the term mobile media to refer to any type of non-traditional telephony service.
}

new mobile contents and applications or the production/consumption processes? The construction of a theory of mobile media - understood as a specific theory within a more general media theory-is a challenging objective for contemporary media studies. For the second time in twenty years we have the opportunity of analysing the emergence of a new 'species' in the media ecology (the first one was the World Wide Web in the 1990s) [7][8]. To understand this process and to develop a theory of mobile media is not just a fashionable objective: it is a vital necessity for media studies. Once again Featherstone indicates the importance of a theoretical approach to mobile media:

The intensity of these changes represents a challenge to theorists who seek to understand the emergent conditions for the generation and transmission of knowledge and its relation to the proliferation of digitalized information and new modes of everyday communication. Theorizing ubiquitous media becomes an integral part of theorizing culture and society today [9].

The development of a theoretical discourse about mobile media needs to be based on the fundamental elements of any theory: 1) the definition of a set of basic concepts and categories for understanding the process, and 2) classification of the components or elements that are involved in the process. In this context, we make a series of reflections on the contents and applications of mobile media. Before developing this theoretical discourse we will briefly summarize the emergence and evolution of the mobile media landscape.

\section{A. From cell phones to multimedia mobile devices}

From a theoretical perspective it no longer makes sense to talk about 'cell phones': we are now dealing with hightech multimedia mobile devices that integrate a wide spectrum of functions and properties. Voice telephony was the main function of a traditional mobile handset; however, in the last decade these devices have mutated into a complex multi-platform system that includes email, a web browser, address book, calendar, clock, games, video camera, GPS, music player, e-book reader, access to radio and television content, and thousands of downloadable and upgradeable applications.

Although this paper is dedicated specifically to mobile contents and applications, we need to remember that a theory of mobile media should also include a set of definitions and taxonomies of the devices. It is undeniable that the device determines the type of media usage the users are involved in. In other words, a theory of mobile media 
must delimit its object: Are we just talking about the socalled 'smartphones' in contraposition to regular' ${ }^{2}$ phones? Can we consider tablets and netbooks as mobile devices? Is a videogame console such as Nintendo DS a mobile device? What about e-book readers like Amazon's Kindle Fire? Can we place these devices in the same category as smartphones? The construction of a solid theoretical discourse should start with these basic semantic foundations.

\section{B. From voice to broadband multimedia contents}

The contents of mobile devices have evolved from verbal to multimedia. For almost one century oral communication was the content of telephones and continued to be so for the first generation (analogue) and second generation (digital) of cell phones. The digitalization of the second generation of mobile communications led to the Short Message Service (SMS) being included in the contents in the 1990s, signalling the beginning of the transformation of this verbal dimension into new modes of mobile communication. Born within the context of radiotelegraphy and as a mechanism for controlling the radio channel, the SMS standard was introduced into the Global System for Mobile Communications (GSM) in 1985. The first SMS was sent over the Vodafone GSM network in the United Kingdom on 3 December 1992, and one year later was commercially developed in Sweden and Finland. After initial slow growth the SMS expanded explosively in the late 1990s [10].

After the success of SMS the mobile industry applied linear logic and put their money on what seemed to be at the time logical extensions of the SMS model. These initiatives consisted mainly in MMS (Multimedia Message Service), in which it was possible to send pictures as well as text, and videoconferencing, that is, not only audio communications but audio and video at the same time. Without exaggerating it can be said that both were complete flops in terms of market adoption. ${ }^{3}$

During the 2000s the multimediatization of mobile devices progressed slowly in a complex process that could be considered one of the possible dimensions of a more general media convergence [13]. During this process cultural industries with the support of mobile operators launched several initiatives to explore the opportunities of this new domain [14], and therefore a vast range of new mobile contents was born during this decade. According to Feijóo et al. [15] the most usual mobile contents are:

- Mobile television and video (broadcasting television and on-demand video services),

- Mobile music, ringtones, back tones, full-tracks, etc. (both in streaming and downloading modes),

- Mobile gaming,

- Mobile adult (images and video),

- Mobile personalization (wallpapers, images, etc.),

- Mobile user-generated content,

- Mobile publishing (books and magazines),

- Mobile advertising,

\footnotetext{
${ }^{2}$ Also called 'feature' phones. It is interesting to note that even the market segment of this device is evolving to include increasingly advanced displays, use of audio full-tracks and cameras.

${ }^{3}$ See the revealing work of Jensen [11] for an examination of MMS, and Feijóo, Gómez-Barroso and Ramos [12] for a general review on including video in the mobile sphere.
}

\section{- Mobile gambling.}

In this context the mobile device 'is not merely another platform for content distribution, and to view it simply as the transformation of existing content into the mobile realm is to neglect some of its most promising aspects' [16].

\section{The explosive diffusion of mobile applications and the emergence of mobile platforms}

The arrival of the iPhone in 2007 and the opening of the Apple App Store on July 2008 created a new technoeconomic model for mobile communications that completely disrupted the structure of the industry and the cautious and 'linear' thinking predominant at the time.

The lesson learnt from the previous stage was that success in providing mobile contents and applications requires the cooperation of all the different players involved. However, because the large number of activities and players in the ecosystem increases the transaction costs it is logical to integrate as many activities as possible or at least keep them under some control. This was the origin of the "platformization" of the mobile media domain [17].

All platforms have a relatively common structure. For instance, Apple's platform is composed of four main components: the iPhone-iPod-iPad as the mobile/portable devices (with Apple iOS as the operating system), the App Store in which applications are available for users to download, the iTunes software as the billing and control system, and a software development kit (SDK) for interested parties. This same model has been imitated, for instance, by Google (the Android suite, the smartphones based on it, its application store, and a set of software facilities for developers) and Microsoft (Windows Mobile, smartphones using this operating system, an application store and the corresponding SDK). In the case of Nokia the model was already partly in place before the iPhone was introduced into the market, and it included its own handsets, the Symbian operating system for mobile devices and the Ovi services and application store. However, the Ovi store has been shut since 2011 and there are considerable uncertainties regarding the evolution of Symbian after the alliance of Nokia with Microsoft. Other major players in the mobile ecosystem have followed similar steps in their approach to building mobile platforms, and, for instance, RIM (Blackberry), Palm, Samsung, Sony-Ericsson, Sun, Qualcomm, vendor independent platforms, the mobile operators themselves (Vodafone, Telefonica, etc.), and even Facebook, have announcedand set up-application stores and software platforms for interested parties.

The App Store was a service created to download applications for the iPhone and iPod Touch; in a few months the market exploded and thousands of applications joined the App Store. The expansion of this market was a sudden dramatic phenomenon: the number of applications went from 500 in July, 2008 to more than 500000 in October 2011 [18]. In October 2008 Google followed Apple and launched the Android Market for mobile devices using the Android operating system. In July 2011 the Android Market included more than 2.5 million applications [19]. In April 2010 the Apple iPad emerged into the mobile media ecosystem and contributed to expanding the number of the App Store applications and users. 
There are a number of differences between the Android Market and the Apple App Store, some of which are mainly of interest to end-users and others to developers [20]:

- Open vs. Closed System: Whereas Apple's system is a closed one, Android Market provides an open environment for developers. In the case of Apple, the applications must be submitted for review and the company is the one who ultimately decides which applications can and cannot be included in the App Store. In the Android Market, developers can publish their applications directly on the market and developers are encouraged to use open-source and Linux platforms. Both systems support community ratings and comments that establish a hierarchy in the market.

- Refunds: The Android Market allows the end-user to obtain a refund if the application is uninstalled within 24 hours of purchase. The Apple App Store does not offer refunds on applications.

- Developer Initiation Fee: Android Market charges a fee of US\$25 to sign up as a developer while the Apple App Store charges $\$ 99$ to become a developer. Both markets receive $30 \%$ of any application sale; however, Apple keeps this 30\% while Google pays the $30 \%$ to the wireless carriers.

- Competition: There is less competition in Android Market for developers trying to bring their new application to the attention of end-users. However, as Android Market is self-organized it has few high quality apps and a lot of junk software (i.e. spam ringtone apps): 'These apps are damaging to companies that are building legitimate Android music apps [...] Developers and users are getting fed up and it's time for Google to clean up the house' [21].

- Earnings: In May 2011, Apple approved its 500,000 th app, $37 \%$ of all apps are free and the average price is US\$3.64 [22]. On 21 May 2011, Google announced that the number of apps in Android Market had increase by 28,000 in April 2011 (57\% of them were free in 2009) [23].

- Amateurism/Open-source culture: The lack of an approval process makes it more possible for hobbyist projects to exist in Android. This platform has attracted more developers from the open source and Linux world who are used to making their applications available for free [24].

As we can see the mobile application market is another battlefield for the big actors of the media ecosystem, but at the same time, the basic agreements between those large armies (mobile device producers, content creators, telephone operators, entertainment and media industries etc.) allow the market to expand. The key actors in the mobile economy have joined forces in various combinations 'to make mobiles an important and distinctive platform for contemporary media consumption, exchange, and production' [25].

In summary, the combination of new possibilities in the handset (touch screen, motion sensor, precise location system, enhanced display, heavy storage, high-quality audio, embedded camera) and the ubiquitous connection to the network has allowed many innovations to be developed, including application stores, accessing content online while on the move, keeping in continuous contact with social networks, consuming content across several media, and taking advantage of the unique features of the mobile domain: personalization and context-awareness (location as a prime example).

\section{Towards a taxonomy of mobile contents and applications}

The first step in constructing a theoretical discourse is to define the concepts. In the mobile domain, a particular fusion between application and content takes place, merging actions and functions with meanings and contexts. A specific differentiation between applications and contents is therefore necessary. According to Wikipedia an application is a 'computer software designed to help the user to perform singular or multiple related specific tasks' [26]. Application software is contrasted with system software and middleware, which manage and integrate a computer's capabilities but are generally not directly applied to perform tasks.Content is a 'set of information and experiences that may provide value for an end-user/audience in specific contexts. Content may be delivered via any medium' [27]. However, from the perspective of user experience, applications and contents seem to be inextricably connected in the mobile environment [28].

The explosion of new devices, applications and contents seems to challenge both definitions. Should the new iMagazines for iPads be considered as a content or an application? And what about digital books? Are they a content or an application? The iPad has an optional iBooks application that can be downloaded from the App Store that displays books and other ePub-format contents downloaded from the iBookstore. In this context: Is the application an interface that permits the user to consume a content?

At the end of the paper we'll come back to the definitions. In the following sections we'll describe the most important classifications of mobile contents (Sections IIV) and applications (Sections VI and VII). Considering that the present research is based in Spain, when possible we'll include examples from the Spanish mobile market in each category.

\section{CONTENT ClassificAtion: GenRe/PurPose}

The mobile content domain consists of a heterogeneous and fragmented digital ecosystem. How can we introduce an order into this chaotic environment? Mobile contents have been classified from different perspectives. As Feijóo et al. indicate, 'most usual classifications are just translations of other industries into the mobile domain and fail to gauge the attributes of mobile content that can drive its evolution' [29].

As the number of items swelled, application and content stores began to classify their products based on a mix of genre criteria (e.g. games), and contextual use criteria (e.g. lifestyle). This particular mix seems to follow the standards of category management in merchandising [30]. But genre-based classifications are not only derived from their relation to the commercial environment and everyday activities: they are also influenced by standard media content. In the beginning of mass media theories researchers considered that media could be used for informing, advertising and amusement. This taxonomy is based on the content genre (e.g. news, advertisement, videogames, etc.) and the final purpose of the communication (e.g. to 
inform, to promote, to play, etc.); originating in the literature, it was taken by traditional media studies and adapted to the mobile communication environment. In this context we can identify different categories of contents, like news, advertising, leisure (books, music, photos and audio-visual contents) and education. In view of their specific characteristics (interactivity, market strength, cultural importance), videogames are usually considered as an independent category.

\section{A. News/Information}

Mobile journalism may be considered from the perspective of the professional (that is the 'mojo' or mobile journalist) or the user. In the first case mobile journalism is a professional practice based on creating and diffusing news with simple portable tools; news items are usually posted either in online publications, social networks like YouTube, newspaper websites or in the print editions of newspapers.

For many journalists 'common mobile phones are increasingly digital media toolkits featuring various combinations and configurations of text and multimedia message capability, still and video cameras, GPS locators, radio and TV receivers, and a range of software applications from games to personal organizers. As a production device and a media form the mobile phone is becoming increasingly interesting to news organizations seeking to make use of both professional and amateur content recorded in the field' [31].

From the perspective of users the SMS information channels should be considered the chief mobile news source, later expanded with the inclusion of MMS. In recent years social platforms like Twitter have become a successful environment for receiving, producing and exchanging news. In Spain the Catalonian Audio-Visual Media Corporation (CCMA) implemented an SMS and MMS information service that adapted broadcast radio and television news into mobile contents. As devices progressively enhance their connecting and computing capabilities, new forms of distributing journalistic content evolve: light mobile websites, Bluetooth (mostly within promotion strategies at commuting points in big cities like in the Madrid subway), QR Codes, off-line downloadable micro-editions (like the sports newspaper Marca), etc. However, since the evolution of smartphones and tablets, branded applications seem to be the most promising way of distributing and consuming mobile news as well as implementing cross-media content distribution in webbased multimedia portals; see, for instance, the Catalonian TV apps ${ }^{4}$ and the Spanish public television TVE video apps $^{5}$ for news and sports. For a recent review of the distribution of mobile journalistic content in Spain see [32].

\section{B. Marketing/Advertising}

As they are strongly linked to the user's everyday life and identity, marketing experts believe that mobile devices are the perfect tool for promoting products and brand images. Mobile marketing includes using mobile platforms for sending messages (SMS, MMS), downloading applications or surfing the web for interactive advertising purposes. Marketing actions in the mobile environ- ment include mobile advertising, mobile couponing, mobile direct marketing, mobile CRM (Customer Relationship Management), mobile branding and other integrated actions in the digital sphere. The implicit danger in the personalization capability of mobile marketing and advertising is that users easily perceive mobile commercial communication as a kind of intrusion in their private life. Consequently, three golden rules should be followed in any marketing strategy in the mobile environment: permission, attractiveness and usefulness [33].

Among the contents most diffused in the mobile media are company logos, wallpapers, audio jingles and files, SMS, MMS, watermarks, advergames and brandgames, WAP portals, etc. [34][35][36]. Lynx's successful Girl Finder, a campaign that included an application produced in Barcelona, videos and user-generated contents, is a good example of second-generation mMarketing (not limited to SMS) [37]. Branded applications provide an attractive combination of brand images, useful functions and tools for users integrated into everyday digital routines. Their increasing use as a relevant branding strategy has given rise to the term 'appvertising'. Many of them take advantage of the mobile device's capacities, such as ubiquitous social networking, GPS location and augmented reality. Nike's True City, Louis Vuitton's networked travel guide Amble or the showroom dress catalogue of the Spanish fashion firm Zara are examples of this.

The Spanish firm Mobile Dreams Factory ${ }^{6}$ is a good example of a specialized, world-class mobile advertising agency. It has developed branded applications and mobile advertising campaigns for some of the most reputed brands in the world, like Coca-Cola, Nestle, Nokia, Heineken and Adidas. It also promotes the Mobile One Alliance $^{7}$, a consortium of mobile advertising agencies that advocates for standardized metrics and formats. Mobile advertising is a relevant player in mobile content distribution as it makes a viable business model that allows content producers and distributors to recoup the costs of adapting existing contents or producing new ones for the mobile environment [38].

\section{Books, music and audio-visual contents}

Leisure contents range from digital literature to songs, movies and TV series. The diffusion of tactile interfaces and high-quality screen devices like in the iPhone has facilitated the reading experience on digital mobile devices. Reading applications allow the user to modify and personalize the font size and colours, mode (portrait or landscape), justification, line spacing, and hyphenation. The arrival of the iPad and a new generation of eReaders and tablets accelerated the expansion of this area of the digital publishing market. One of the first iMagazines for iPad to be presented in Spain was Muy Interesante, a popular monthly science magazine, in December 2010.

Music is present in mobile devices in different formats, from call-bells and ringtones to the complete discography of the user's favourite artist. The portability of music has a long history; the evolution of ubiquitous music took giant leaps forward with the Sony Walkman in the 1980s, the digital music players in the 1990s, and the iPod in the 2000s. According to Goggin 'as mobile phones developed

\footnotetext{
${ }^{4}$ http://www.3cat24.cat/mobils

5 http://www.rtve.es/moviles
} 
in sophistication, especially adopting computer processors, operating systems, applications, and storage capacity, handset companies quickly saw the potential for handsets to be positioned in the portable music player market. Once it was possible for mobile phones to store music (...) companies developed and marketed mobiles as music players' [39].

Audio-visual content includes streaming mobile television and other audio-visual textual productions created to be downloaded or consumed in social media like YouTube. According to Orgad, mobile television 'receives considerable attention in current debates on new media and communication technologies'; in these forums positions range from 'enthusiastic forecasts (that) suggest an explosion in demand' to discussions and panels about 'The Death of Mobile TV' [40]. Orgad considers that the mobile TV technology 'is mainly at the trial and commercial launch stages. Its development will depend on technological, commercial, social, political, regulatory and other factors that are unclear' [41].

More successful experiences have been the diffusion of mobisodes and other complementary micro-texts connected to larger narrative experiences like TV series, such as Lost [42] or 24 [43]. Short formats like trailers, sneak peaks, and music video clips seem to have been born for the mobile media environment. Mobile media have also demonstrated themselves to be an ideal channel for the diffusion of adult content audio-visual productions. Supervillanos (2005) is a good example of audio-visual production for mobile devices; produced by Globomedia, the series included 40 episodes of 3' and must be considered the first mobile series of Spanish television.

\section{Videogames}

In 1998 Nokia pre-loaded Snake-a classic videogame first released during the mid 1970s in arcades-in their phones. Talking about 'mobile gaming' generally includes any videogame played on a mobile phone, smartphone, PDA, handheld computer or portable media player. However, handheld videogame systems such PlayStation Portable or Nintendo DS - that were already in the market long before the arrival of Snake to Nokia's terminals-are usually considered under a different content category.

The arrival of the iPod Touch and the iPhone led to the outburst of videogames for mobile devices. Before the current model of application stores was developed, mobile games were usually downloaded via the mobile operator's network or the device creator's online store; in some cases they were also pre-loaded into the mobile handsets when purchased.

The development of mobile videogames has gone hand in hand with the development of the technology inside the devices. The inclusion of digital cameras popularized cell phones and at the same time increased the quality of the screen and the memory. Mobile games took advantage of these technical specifications of the new generation of devices.

Many mobile games employ the technologies in the device itself (i.e. SMS, MMS, GPRS, camera). According to de Souza e Silva and Hjorth, these urban mobile games that include location identification 'remind us of the pivotal role games play in understanding phenomena around embodiment/disembodiment and mobility/ immobility. As mobility becomes not only a key indicator of material practices but also use of wireless, mobile, portable, and handheld devices is gradually increasing and diversifying across every sector of education, and across both the developed and developing worlds. It is gradually moving from small-scale, short-term trials to larger more sustained and blended deployment' [44].

The platform environment, like the one in Apple's IOS or Google's Android, radically broadened the supply and access to this kind of content and opened up the digitalgame industry to a myriad of small developers and producers.

According to Goggin 'in a little over a decade, mobile gaming has been established as a significant part of contemporary gaming cultures. It has not proven as lucrative as hoped, but in various forms it is firmly established as a central part of mobile phone culture-whether as embedded games on a handset, downloadable games from a portal or premium rate number, or apps' [45]. In this context, Spain is an important actor in the mobile gaming industry [46]. Companies like Digital Legends ${ }^{8}$ have produced sophisticated high-tech games like Kroll, one of the first 3D games for the iPhone, or Bruce Lee Dragon Warrior HD for the iPad.

\section{E. Education}

Like mobile television, educational contents seem to be one of the big challenges and promises of the new new media. Compared to other types of learning activity, mobile learning is obviously focused on moving learners:

We learn across space as we take ideas and learning resources gained in one location and apply or develop them in another. We learn across time, by revisiting knowledge that was gained earlier in a different context, and more broadly, through ideas and strategies gained in early years providing a framework for a lifetime of learning. We move from topic to topic, managing a range of personal learning projects, rather than following a single curriculum [47].

Mobile learning can include a broad spectrum of multimedia contents, games, simulations and applications. In the specific case of Spain, an early example of edugaming is Emergencia 112, a feature phone game developed in 2006 by a group of medical doctors in cooperation with health authorities designed to teach users first aid techniques.

The taxonomy based on genre/purpose is very popular but, like any other classification, sometimes it is not easy to find a category for hybrid contents. New categories like infotainment or edutainment are evidence of these tensions.

\section{CONTENT CLASSIFICATION: ORIGINS}

As early as 2005, Feldmann [48] introduced a distinction between specific and repurposed mobile content, which underlies the convergent nature of mobile media. According to Scolari et al. [49] mobile contents can be classified into specific, adapted and non-adapted. Specific contents are created especially for mobile devices, while adapted contents - which generally come from the web or television-are transformed in order to be distributed through this new channel; finally, non-adapted contents arrive directly to the mobile device without having been

\footnotetext{
${ }^{8}$ http://www.digital-legends.com
} 
transformed. An expanded version of this taxonomy was presented in Feijóo et al. [50]. According to these researchers mobile contents can be classified into four categories that are not mutually exclusive:

- Adapted, for existing information (coming from different media) that has been adjusted in order to be displayed and used on a mobile. For example: mobile news, web search adapted to mobiles, mobile mail, etc. Light versions of mobile news portals, like elmundo.es, are good examples of this category.

- Repurposed, for creative contents that have been reused and adapted to mobility. For example: mobile TV, mobile music, mobile entertainment, etc. Mobile versions of PC or console games are paradigmatic cases of this category.

- Original or specific, for creative contents that have been designed with mobility in mind. For example: new mobile music, gaming, etc. The first Spanish mobile series, Supervillanos, mentioned above, is an example of this.

- Augmented, for contents (of any type) that use the additional and specific properties of mobile systems to increase the value and interest of the information for users. For example: location-aware contents. Padelphone, for instance, is an application that allows nearby courts to be identified and booked. Similarly, Farmadroid is an Android application for locating open pharmacies.

\section{CONTENT ClassifiCATION: NARRATIVE STRATEGY}

Transmedia storytelling is one of the key processes of contemporary media ecology [51]. According to Jenkins, in the ideal form of transmedia storytelling 'each medium does what it does best-so that a story might be introduced in a film, expanded through television, novels, and comics, and its world might be explored and experienced through game play. Each franchise entry needs to be selfcontained enough to enable autonomous consumption. That is, you don't need to have seen the film to enjoy the game and vice-versa' [52]. Mobile content usually occupies an important place in transmedia strategies, for example, in the diffusion of mobisodes that expand the original content. Experiences like Fox's 24 or ABC's Lost have demonstrated the strength of this kind of audiovisual content for expanding a narrative world and consolidating a brand [53][54]. Transmedia strategies also include the creation of applications, including gameslike 24: Conspiracy-or interactive expansions of television content-like Herod's Lost Tomb by National Geographic.

From a narratological perspective mobisodes can be classified into autonomous/dependent contents. To identify autonomous contents we must ask the following question: Can this mobile content be understood without watching the original television show or movie? If the answer is "yes", then the mobisode is an autonomous content. However, if the mobisode requires that the mother-text is consumed in order to be interpreted, then we're dealing with a dependent content.

According to Jenkins [55], transmedia storytelling also includes the creation of user-generated contents in platforms like blogs, wikis, etc. These environments should be considered an open-source story-creation machine that allows users to enrich the fictional world usually outside the copyright owner's control. From this perspective, mobile contents can be classified into official/usergenerated contents. Official contents are part of the canon, while user-generated contents integrate the heterogeneous world of fandom. Portals like Fanfiction.net ${ }^{9}$ have already created a specific interface for accessing fan-made contents from mobile devices.

\section{CONTENT ClassificATION: STORAgE}

Mobile contents can be stored in a cloud server or they can be downloaded on the mobile device. The first generation of mobile contents was mainly designed to be downloaded; however, the diffusion of cloud computing in recent years has expanded this sector of the digital economy. The creation of the Amazon Elastic Compute Cloud (EV2) is a good example of this expansion: even though it is still a retailer, Amazon's share values have more than doubled since it launched its cloud services in 2007 [56]. Apple is also a big player in the cloud game, and services like Google Music, Amazon Cloud Player, Apple iCloud are mutating the ways of consuming media contents [57].

\section{Application Classification: Genre/Purpose}

As we have just seen, creating a taxonomy of mobile contents is a complex issue, and we could describe many other oppositions or categories in which mobile contents could be included. In any case, this first taxonomic map of mobile contents could be useful for developing a classification of mobile applications and at the same time refining the definition of both concepts (content and application).

Applications can also be classified according to their genre or purpose. For example, in October 2011 the Apple App Store had almost half a million applications, which includes any kind of free or paid software for Apple's mobile devices (iPod, iPhone, iPad). These applications are usually organized in 'categories' similarly to other services, like the Android Market. Google's initiativethe most important competitor of the Apple App Storehad more than 250,000 applications in July 2011, distributed in two large categories: Applications (26 subcategories) and Games (8 sub-categories). Other companies, like Nielsen, have also organized the applications in their reports on the mobile market into categories (see Table I).

As we can see, the genre/purpose classification of the applications generates the same problems as when it is applied to contents: the limits between different applications are not clear and the categories are not standardized. As for contents, even in this case the most usual classifications are just translations of other industries into the mobile domain [61].

\footnotetext{
${ }^{9}$ http://m.fanfiction.net
} 
TABLE I.

APPLiCATION CATEGORIES ACCORDING TO APPLE [58], GOOGLE [59] AND NIELSEN [60]

\begin{tabular}{|c|c|c|}
\hline Apple's App Store & Android Market & Nielsen \\
\hline Games & $\begin{array}{l}\text { Games (Arcade and } \\
\text { Action, Racing, } \\
\text { Causal, Live Wall- } \\
\text { paper, Sports, Brain } \\
\text { and Puzzle, Cards } \\
\text { and Casino) }\end{array}$ & Games \\
\hline \multirow[t]{3}{*}{ Books } & Books and Reference & \\
\hline & Libraries and Demo & \\
\hline & Comics & \\
\hline Entertainment & Entertainment & Entertainment \\
\hline Education & Education & $\begin{array}{l}\text { Education/ } \\
\text { /Learning }\end{array}$ \\
\hline Lifestyle & Lifestyle & \\
\hline Utilities & Tools & \\
\hline Travel & Travel and Local & Travel \\
\hline \multirow[t]{3}{*}{ Music } & Music and Audio & Music \\
\hline & Communication & Communication \\
\hline & Media and Video & Video and movies \\
\hline Photography & Photography & \\
\hline Sports & Sports & Sports \\
\hline \multirow[t]{2}{*}{ News } & News and Magazines & News \\
\hline & News Weather & \\
\hline Productivity & Productivity & Productivity \\
\hline Medical & Medical & \\
\hline Navigation & Transportation & $\begin{array}{l}\text { Maps/navigation/ } \\
\text { /search }\end{array}$ \\
\hline $\begin{array}{l}\text { Healthcare \& } \\
\text { Fitness }\end{array}$ & Health and Fitness & $\begin{array}{l}\text { Household/ } \\
\text { /Personal care }\end{array}$ \\
\hline Social Networking & Social & Social Networking \\
\hline Weather & Weather & Weather \\
\hline Finance & Finance & Banking/Finance \\
\hline \multirow[t]{2}{*}{ Business } & Business & \\
\hline & Shopping & Shopping/retail \\
\hline \multicolumn{3}{|l|}{ Reference } \\
\hline & & Dining/Restaurant \\
\hline & & Food/Drink \\
\hline & Personalization & \\
\hline & Themes & \\
\hline & Widgets & \\
\hline
\end{tabular}

\section{APPLICATION ClASSIFICATION: ORIGINS, NARRATIVE STRATEGY AND STORAGE}

The taxonomy based on the origins of the content developed by Feijóo et al. [62] can be adapted to applications:

- Adapted or repurposed, for applications coming from other devices that have been adjusted for display and use on a mobile. For example, an application originally developed for the Mac like Keynote may be adapted to the iPad, or a videogame originally developed for Nokia or iOS can be adapted to Android.

- Original or specific, for applications that have been designed with mobility in mind, like most of the applications developed in recent years.
- Augmented, for applications that use the additional and specific properties of mobile systems (such as location-awareness) to increase the value and interest of the application for users.

The taxonomy based on the narrative strategy can also be applied to certain application categories, for example, games that expand the narrative world of the original product (film, TV series, book, etc.). Applications like Buenafuente-an extension of the homonymous Spanish late-night show-or Águila Roja Puzzle-a game based on the historical fantasy fiction series Águila Roja-are good examples of dependent interactive applications that expand a narrative universe.

In terms of storage, mobile applications are usually downloaded and installed in the mobile device, so they should be considered as an interface that connects users and contents situated in the cloud. This connecting function of mobile applications-e.g. the Wired application is the interface that opens access to the content, in this case Wired Magazine -is the key element for reopening the discussion on the definition and the differences between applications and contents.

\section{TOWARDS A GENERAL DEFINITION OF MOBILE CONTENTS AND APPLICATIONS}

Since the beginning of the digital era, software applications like MS Word and Adobe Photoshop have been considered tools for doing, while digital contents have been considered texts for knowing. The first ones are instruments for accomplishing a task (writing a letter, modifying a photo, etc.) and the second ones are textual units of any kind (written, iconic, multimodal, interactive, etc.) that convey a meaning.

The arrival of a new generation of mobile devicessmartphones and especially tablets-has led to applications becoming more than just tools for doing: they are also involved in distributing contents. In other words, applications take part in the knowing process.

The iMagazines born under the umbrella of the iPad are a good example of this extended function of the application: the user downloads an application that has to be fed with new contents every month (week, day). In this context an application is more than computer software designed to help the user to perform a task or to solve a problem: an application is also an interface that increasingly connects the users with the contents. Since the interface-application participates in creating the sense of the text-it is not the same to read an article in the printed edition as it is to read it on the iPad touch-screen-we could say that the application shares some characteristics with the content [63][64][65][66].

In this context we can re-organize the classical division between applications (doing) and contents (knowing) and consider the mobile apps as an interface that connects the users with contents for knowing and tools for doing. The contents could be written texts, images, videos, multimodal and/or interactive. As we have shown, these contents can be classified according to their genre (information, marketing, etc.), origin (adapted, specific, etc.) or narrative strategy (autonomous, dependent, etc.). The mobile application is the place where the user meets and interacts with the content. 
Tools are any piece of software designed for accomplishing a specific task, like sending an email, writing a text or creating a multimedia presentation. A taxonomy of tools can be developed following different criteria, like genre/purpose (the most popular classification), narrative strategy or origin. The mobile application is the place where the user interacts with the tool to accomplish the task.

Between the tools and the contents there is a series of hybrid environments-like the social network clients (Facebook, Echofon, Foursquare, Twitterlator, etc.)-that integrate characteristics of both of them (tools for doing and contents for knowing). Some tools directly related to shared content production and diffusion-i.e. social networks-are acquiring a complex multifunctional dimension that prefigures them as a sort of meta-tool or even a new kind of multi-device platform (Facebook is a good example of this, and Google+ seems to be going in the same direction). This could also be part of an observable trend towards multi-device coherent platforms (performing the functional and aesthetic fusion between Chrome and Android or between IOs and Lionhead) [67].

Another property that characterizes applications is the fact that they are downloaded in the mobile device; similarly, tools must also be downloaded, while contents may be downloaded or consumed in streaming (from the cloud). However, this difference is rapidly disappearing because consolidated platforms like Google/Android and Apple/IOs are pushing applications into the cloud, which also makes things easier for developers and content produces, and favours homogeneity in a fragmented environment [68].

Beyond tools and contents we can identify a complex set of relationships with other technological systems: the media system, the World Wide Web, cloud computing and the general digital technology system (See Figure 1).

\section{CONCLUSIONS}

Mobile communication is an emerging area of the media ecology and at the same time one of the most challenging research fields of media studies. The field is so effervescent that any theoretical approach must be reviewed every few months. It is therefore not so easy to develop concepts, categories and taxonomies: the mobile market introduces new devices, applications and products every week, and any one of these could be a disruptive element in the mobile ecosystem.

In this paper we have defined and classified mobile applications and contents considering the latest technological developments in the field. The explosion of tablets, new interactive contents and applications into the market has theoretical consequences that we have discussed in this article. Considering the dynamics of the mobile ecology, any definition and taxonomy must be kept under constant scientific surveillance because new developments can destabilize the theoretical discourse at any moment.

\section{REFERENCES}

[1] T. O'Reilly, What Is Web 2.0 Design Patterns and Business Models for the Next Generation of Software, 2005. Online version: http://www.oreillynet.com/pub/a/oreilly/tim/news/2005/09/30/wha t-is-web-20.html

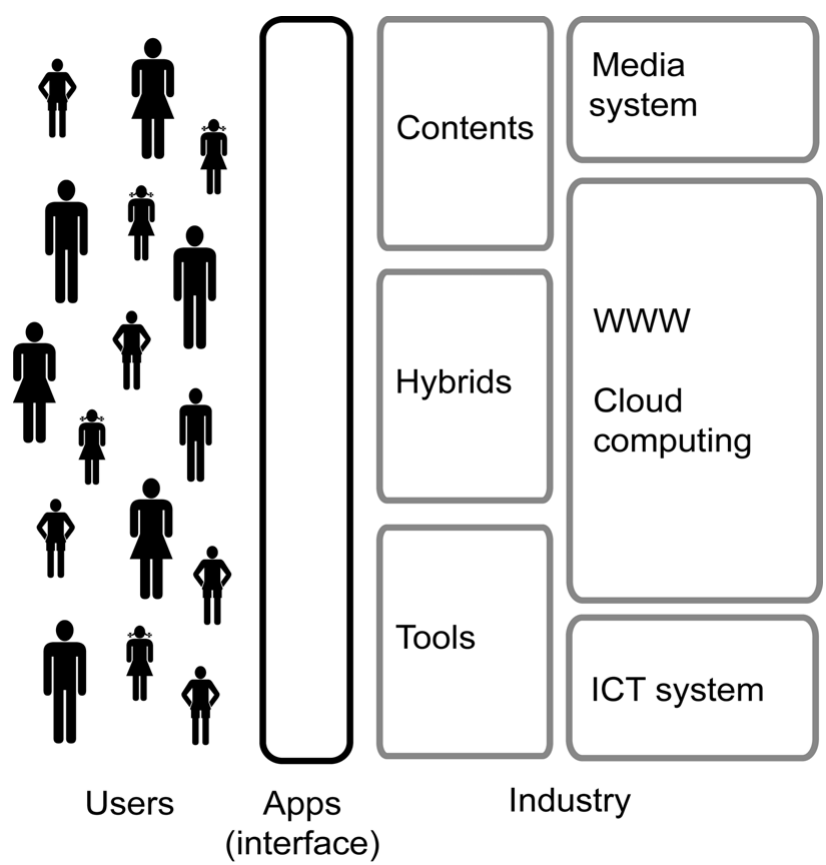

Figure 1. Applications, contents and tools

[2] C.A. Scolari, H. Navarro, I. García, H. Pardo Kuklinski and J. Soriano, "The Barcelona Mobile Cluster:Actors, Contents and Trends", International Journal of Interactive Mobile Technologies, vol. 3 (3), pp. 47-54, 2009. Online version: http://onlinejournals.org/i-jim/article/view/814

[3] G. De Prato, C. Feijóo, D. Nepelski, M. Bogdanowicz, and J.P Simon, Born digital / Grown digital. Assessing the future competitiveness of the $E U$ videogame software industry. Luxembourg: Institute for Prospective Technological Studies. European Commission, 2010.

[4] A. Jaokar and A. Gatti, Open mobile. Understanding the impact of open Mobile: implications for telecoms/devices, web, social networks, media and personal privacy. London: Futuretext, 2010.

[5] R.K. Logan and C.A. Scolari, "mCommunication. The emergence of mobile communication within the media ecosystem", Explorations in Media Ecology (EME), vol. 2010, pp. 169-184, 2010.

[6] M. Featherstone, "Ubiquitous Media: An Introduction”, Theory, Culture \& Society 26(2-3), p. 2, 2009. http://dx.doi.org/10.1177/ 0263276409103104

[7] R.K. Logan and C.A. Scolari, op. cit.

[8] C.A. Scolari, "Media Ecology. Map of a theoretical niche", Quaderns del CAC, 34, vol. XIII (1), pp. 157-25, 2010. Online version:

http://www.cac.cat/pfw files/cma/recerca/quaderns_cac/Q34_Scol ari_EN.pdf

[9] M. Featherstone, op. cit., p. 3.

[10] SMS. (n.d.). In Wikipedia. Retrieved October 12, 2011, from http://en.wikipedia.org/wiki/SMS

[11] S. Jensen, "Default thinking: why mobile services are setup to fail”. In R. Harper, L. Palen, and A. Taylor, Eds. The inside text: social, cultural and design perspectives on SMS, London: Springer, 2005.

[12] C. Feijóo, J.L. Gómez-Barroso and S. Ramos, "Los medios de comunicación en Internet móvil: la televisión como modelo aún pendiente de éxito", El Profesional de la Información, 19(6), pp. 637-644, 2010.

[13] C. Feijóo and J.L. Gómez-Barroso, "Factores clave en el acceso móvil a contenidos”, El Profesional de la Información, 18(2, March-April, pp. 145-154, 2009.

[14] J.M. Aguado and I.J. Martínez, "From Mobile Phones to Mobile Media: Current Developments in Mobile Phone-Based Cultural Consumption”, Mobile Media 2007, G. Goggin and L. Hjorth, Eds. Sydney: University of New South Wales, pp. 47-57, 2007.

[15] C. Feijóo, I. Maghiros, F. Abadie and J.L. Gómez-Barroso, "Exploring a heterogeneous and fragmented digital ecosystem: 
Mobile content”, Telematics and Informatics, 26(3) August 2009, pp. 282-292 http://dx.doi.org/10.1016/j.tele.2008.11.009

[16] C. Feijóo, I. Maghiros, F. Abadie and J.L. Gómez-Barroso, op. cit., p. 4.

[17] P. Ballon, P., "The platformisation of the European mobile industry”, Communications \& Strategies (75), pp. 15-34, 2009.

[18] Apple Special Event - October, 4 2011. Online video: http://events.apple.com.edgesuite.net/11piuhbvdlbkvoih10/event/i ndex.html

[19] Nickinson, P. "Android Market now has more than a quartermillion applications”, AndroidCentral, posted on July, 142011 http://www.androidcentral.com/android-market-now-has-morequarter-million-applications

[20] M. Dorf, M. Android Market Versus Apple App Store, posted on May 10, 2010 http://ezinearticles.com/?Android-Market-VersusApple-App-Store\&id=4266917

[21] J.L. Johansen, Google's mismanagement of the Android Market, posted on June, 27, 2010 http://nanocr.eu/2010/06/27/googlesmismanagement-of-the-android-market

[22] M. Wehner, Apple approves its 500,000th app, but do you care?, posted on May 24, 2011 http://news.yahoo.com/blogs/technologyblog/apple-approves-500-000th-app-care-160140999.html

[23] R. Wauters, "Android To Surpass Apple’s App Store In Size By August 2011", TechCrunch, posted on May, 52011 http://techcrunch.com/2011/05/05/android-to-surpass-apples-appstore-in-size-in-august-2011-report-exclusive/

[24] Pingdom, The mobile app divide: Free rules on Android, paid rules on iPhone, posted on August 27, 2010 http://royal.pingdom.com/2010/08/27/the-mobile-app-divide-freerules-on-android-paid-rules-on-iphone

[25] G. Googin, Global Mobile Media, London: Routledge, 2010, p. 121.

[26] Application. (n.d.). In Wikipedia. Retrieved October 12, 2011, from http://en.wikipedia.org/wiki/application

[27] Content. (n.d.). In Wikipedia. Retrieved October 12, 2011, from http://en.wikipedia.org/wiki/content

[28] J.M. Aguado, C. Feijóo and I. Martínez (2010) “Mobile Ecosystem and Digital Content: Keys for a Personal, Social and Ubiquitous Internet”, in Business Models for a Digital Economy: The Value of Content, Pamplona: University of Pamplona (Spain), 2010.

[29] C. Feijóo, I. Maghiros, F. Abadie and J.L. Gómez-Barroso, op. cit.

[30] I.J. Martínez and J.M. Aguado, "Conceptual and Operative Aspects of e-Merchandising”, International Journal of Internet Marketing and Advertising (4) 2/3, 197-212, 2008.

[31] D. Cameron, "Mobile journalism: a snapshot of current research and practice”. Paper presented at The End of Journalism? Technology, Education and Ethics Conference, University of Bedfordshire, UK, 17th-18th October 2008, p. 5. Online version: http://theendofjournalism.wikidot.com/davidcameron

[32] J.M. Aguado and A. Castellet, "Contenidos informativos en el ecosistema móvil: horizontes y desafíos”. In M.A. Cabrera (Ed.) Evolución Tecnológica y Cibermedios. Sevilla: Comunicación Social Ediciones, 2010, pp. 129-146.

[33] J.M. Aguado and I.J. Martínez, "Mobile Media Implicit Cultures: Towards a Characterization of Mobile Entertainment and Advertising in Digital Convergence Landscape”, Observatorio OBS*, 3/1, 2009, pp. 78-93.

[34] T. Ahonen, T. Kasper and S. Melkko, 3G Marketing: Communities and Strategic Partnerships, Chichester: John Wiley and Sons, 2004. http://dx.doi.org/10.1002/0470011181

[35] R. Mathieson, Branding Unbound; The Future of Advertising, Sales, and the Brand Experience in the Wireless Age, New York: Amacom, 2005

[36] T. Weiss, Mobile Strategies: Understanding Wireless Business Models, MVNOs and the Growth of Mobile Content, London: Futuretext, 2006

[37] C.A. Scolari, H. Navarro, I. García, H. Pardo Kuklinski and J. Soriano, op. cit.

[38] C. Feijóo, J.L. Gómez-Barroso and I.J. Martínez, "Nuevas vías para la comunicación empresarial: publicidad en el móvil”, El Profesional de la Información, 19/2, 2010, pp. 140-148.
[39] G. Googin, Global Mobile Media, London: Routledge, 2010, p. 97.

[40] S. Orgad, "Mobile TV. Old and New in the Construction of an Emergent Technology”, Convergence, vol 15(2), pp. 197, 2009. http://dx.doi.org/10.1177/1354856508101583

[41] Ibidem, p. 198

[42] C.A. Scolari, "Narrativa transmediática, estrategias cross-media e hipertelevisión”, Lostología. Estrategias para entrar y salir de la isla, A. Piscitelli, C.A. Scolari and C. Maguregui, Buenos Aires: Ed. Cinema, 2011.

[43] C.A. Scolari, "Transmedia Storytelling. Implicit consumers, narrative worlds and branding in contemporary media production”, International Journal of Communication, vol. 3, pp. 586606, 2009. Online version: http://ijoc.org/ojs/index.php/ijoc/article/view/477

[44] A. de Souza e Silva and L. Hjorth, "Playful Urban Spaces: A Historical Approach to Mobile Games", Simulation \& Gaming, vol. 40: 5, p. 10, 2009

[45] G. Goggin, op. cit., p. 97.

[46] C.A. Scolari, H. Navarro, I. García, H. Pardo Kuklinski and J. Soriano, op. cit.

[47] M. Sharples, J. Taylor and G. Vavoula, “Towards a Theory of Mobile Learning”. In H. van der Merwe \& T. Brown, Mobile Technology: The Future of Learning in Your Hands, mLearn 2005, 4th World Conference on mLearning, Cape Town, 25-28 October 2005. Cape Town: mLearn 2005 Online version: www.compassproject.net/sadhana/teaching/readings/sharplesmobi le.pdf

[48] V. Feldmann, Leveraging Mobile Media. Cross-Media Strategy and Innovation Policy for Mobile Media Communication. Heidelberg-New York, Physica Verlag, 2005.

[49] C.A. Scolari, H. Navarro, I. García, H. Pardo Kuklinski and J. Soriano, op. cit.

[50] C. Feijóo, I. Maghiros, F. Abadie and J.L. Gómez-Barroso, op. cit.

[51] H. Jenkins, Convergence Culture. Where old and new media collide, New York: NYU Press.

[52] H. Jenkins, “Transmedia Storytelling. Moving characters from books to films to video games can make them stronger and more compelling”, Technology Review, January, 15 2003. Online version: http://www.technologyreview.com/Biotech/13052/

[53] C.A. Scolari, 2009, op. cit.

[54] C.A. Scolari, 2011, op. cit.

[55] H. Jenkins, 2006, op. cit.

[56] D. Blankenhorn, “Amazon Is Still a Retailer”, Seeking Alpha, june 17, 2011. Online version: http://seekingalpha.com/article/275498amazon-is-still-a-retailer

[57] P. Boutin, “Amazon's and Google’s Cloud Services Compared”, Gadgetwise, June 6, 2011. Online version: http://gadgetwise.blogs.nytimes.com/2011/06/06/amazons-andgoogles-cloud-services-compared

[58] App Store Metrics: Application Category Distribution, July, 2011. Online version: http://148apps.biz/app-store-metrics/?mpage=catcount

[59] AndroLib application categories, July, 2011. Online version: http://www.androlib.com/android.category.applications-j.aspx

[60] Nielsen Wire, Play Before Work: Games Most Popular Mobile App Category in US, July 6, 2011. Online version: http://blog.nielsen.com/nielsenwire/online_mobile/games-mostpopular-mobile-app-category/

[61] C. Feijóo, I. Maghiros, F. Abadie and J.L. Gómez-Barroso, op. cit.

[62] Ibidem.

[63] C.A. Scolari, "Towards a semio-cognitive theory of HCI”. In Extended abstracts of the ACM CHI 2001 Conference, 8586. New York: ACM Press.

[64] C.A. Scolari, Hacer Clic. Hacia una sociosemiotica de las interacciones digitales. Barcelona: Gedisa, 2004.

[65] C.A. Scolari, "The sense of the interface: applying Semiotics to HCI research”, Semiotica, vol. 177, 2009, pp. 1-27. http://dx.doi.org/10.1515/semi.2009.067

[66] J.M. Aguado, C. Feijóo and I.M. Martínez, op. cit. 
[67] Ibidem.

[68] V. Nandlall, “Enter the Cloud Phone”, Vision Mobile, 2010. Online version: http://www.visionmobile.com/blog/2010/08/enterthe-cloud-phone

\section{AUTHORS}

Carlos A. Scolari is professor at the Universitat Pompeu Fabra (Barcelona, Spain) and member of UNICA research group (e-mail: carlosalberto.scolari@upf.edu).
Juan Miguel Aguado is professor at the Universidad de Murcia (Murcia, Spain) (e-mail: jmaguado@um.es).

Claudio Feijóo is professor at the Universidad Politécnica de Madrid (Madrid, Spain) (e-mail: claudio.feijoo@gmail.com).

This work was supported by the Ministerio de Ciencia e Innovación de España (CSO-2009-07108 (Subprograma SOCI). Manuscript received 21 November 2011. Published as resubmitted by the authors 30 March 2012. 